Int. J. Electrochem. Sci., 14 (2019) 6257 - 6266

International Journal of

ELECTROCHEMICAL

SCIENCE

$\underline{\text { WWW.electrochemsci.org }}$

\title{
The Effect of Air on Electrochemical Behavior of Activated Carbon at Negative Potentials in Aqueous $\mathrm{Li}_{2} \mathrm{SO}_{4}$ Electrolyte
}

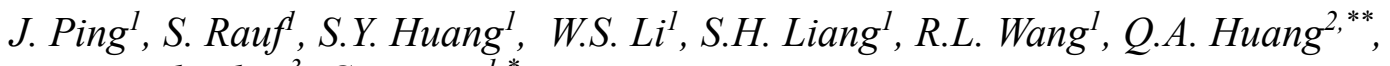 \\ V.V. Morchenkov ${ }^{3}$, C.P. Yang ${ }^{1, *}$ \\ ${ }^{1}$ Faculty of Physics and Electronic Technology, Hubei University \\ ${ }^{2}$ College of Science / Institute for Sustainable Energy, Shanghai University, Shanghai 200444, China \\ ${ }^{3}$ Institute of Metal Physics Ural Branch of the Russian Academy of Sciences, 620990, Ekaterinburg, \\ Russia \\ *E-mail: 1042938556@qq.com (C.P. Yang), hqahqahqa@163.com (Q.A. Huang)
}

doi: 10.20964/2019.07.07

Received: 13 January 2019 / Accepted: 28 March 2019 / Published: 10 June 2019

The electrochemical behavior of activated carbon (AC) has been studied in the presence of air at negative potentials in $0.5 \mathrm{M} \mathrm{Li}_{2} \mathrm{SO}_{4}$ aqueous electrolyte applying the linear sweep voltammetry (LSV). The AC electrodes of low mass loading are disposed and found with distorted LSV curves at constant scan rate, rather than formation of symmetric rectangular shape. Such unusual phenomenon for AC in the electrolyte exposed to air alternatively can be reflected by the discharge capacity of $145 \mathrm{mAh} / \mathrm{g}$ with a pretty high coulombic efficiency (332\%) obtained in the galvanostatic charge-discharge (GCD) test. Meanwhile, the variation in current with scan rate at fixed potentials corresponds to the remarkable deviation of exponent in the power-law equation from the value 1 . The oxidative effect of $\mathrm{O}_{2}$ and $\mathrm{H}_{2} \mathrm{O}$ is investigated to explain the abnormal electrochemical behavior of AC. In the vessel with $\mathrm{N}_{2}$ flow, AC turns to exhibit recognizable capacitive behavior without considering residual dissolved oxygen in the electrolyte. The self-discharging of $\mathrm{AC}$ from $0 \mathrm{~V}$ to around $-0.2 \mathrm{~V}$ without any external bias is observed in the electrolyte of low level of dissolved oxygen. The above results show the improved electrochemical stability of AC in the absence of air, providing information of value based on application for aqueous lithium-ion hybrid supercapacitors using AC anode.

Keywords: activated carbon (AC); linear sweep voltammetry (LSV); air; oxidative effect; selfdischarging; electrochemical stability

\section{$\underline{\text { FULL TEXT }}$}

(C) 2019 The Authors. Published by ESG (www.electrochemsci.org). This article is an open access article distributed under the terms and conditions of the Creative Commons Attribution license (http://creativecommons.org/licenses/by/4.0/). 